to displace the beam in a definite manner, than upon the magnitude of the displacement so p:oduced. As in other instruments whose operation depends upon similar principles, e.g. galvanometers, it is useless to endeavour to increase the sensitiveness by too near an approach to instability, because the effect of casual disturbances is augmented in the same proportion as that of the forces to be estimated. If the time of vibration be halved, the displacement due to a small excess of weight is indeed reduced in the ratio of four to one, but it is not necessarily rendered any more uncertain. The mere diminution in the amount of displacement may be compensated by lengthening the pointer, or by optical magnification of its motions. By the method of mirror reading such magnification may be pushed to almost any extent, but I am dealing at present only with arrangements adapted for ordinary use.

In the balance (by Oertling) that I am now using, the scale divisions are finer than usual, and the motion of the pointer is magnified four or five times without the slightest inconvenience by a lens fixed in the proper position. The pointer being in the same plane as the scale divisions, there is no sensible parallax. In this way the advantage of quick vibrations is combined with easy visibility of the motion due to the smallest weights appreciable by the balance.

To illuminate the scale, the image of a small and distant gas flame is thrown upon it by means of a large plate-glass lens. This artificial illumination is found to be very convenient, as the instrument stands at some distance from a window, but it is not at all called for in consequence of the use of the magnifying lens.

\section{ON THE DEVELOPMENT OF PERIPATUS ${ }^{1}$}

$A$ MONG the acquisitions I made during my journey to the West India Island of Trinidad, a rich collection of Peripatus stands in the first rank. This has put me in a position to correct many mistakes, and to contribute a good deal to the knowledge of the histological anatomy of this interesting animal form, as well as especially to follow the process of development from beginning to end. Postponing for the present the anatomy of the adult animal, inasmuch as we have on this subject a good many studies, some of which are very good (for instance, that of Gaffron in Zool. Beiträge, edited by Dr. A. Schneider), I shall confine myself to a preliminary notice of the earliest stages of the development of Peripatus, although my investigations have not as yet been brought to a conclusion, nor have I been able to devote any attention to the development of the organs. I do this chiefly because the treatise published by Moseley and Sedg. wick from the posthumous notes of Balfour contains some representations of embryos and cross-sections of the same, upon whose accuracy in details I, with my rich and well preserved collection of specimens, and observations on fresh objects, must cast some doubt, and the interpretation of which does not bear investigation. And yet these already serve as evidence for some theoretical explanations of embryonic processes in other groups of animals, which it would be well to avoid in such a case.

I collected in Trinidad over a hundred specimens of Peripatus E:twardsii, and a small number of a new species which is distinguished by its size from all those hitherto known, and which may briefly be thus characterised : The females, which are considerably larger than the males, attain a length of $15 \mathrm{~cm}$. and a diameter of $8 \mathrm{~mm}$.; the males grow to a size oi about ro $\mathrm{cm}$. Their colour is a plain reddish brow $n$ above, darkening a little towards the middle line of the back, and groxing pale a little towards the sides. The head, or, more correctly, the forehead, as well as the antennæ, is black, and marked off on the dorsal side by a light yellow necklace, which is often slightly interrupted in the middle, from the rest of the body. The under side is of a dark flesh colour. This species is especially characterised by possessing forty-one to forty-two pairs of feet, which is the highest recorded number, and a number which differs greatly from that of all other species. I call this new species Peripatus torquatus.

The ovaries are two small, elongated bodies, which are gene rally united along their whole length, and so appear as a narrow, spindle-shaped body, which is connected by one or often by two delicate muscular threads to the body wall. The ovaries are prolonged into the two horns of the uterus, which, each forming a bow with several curves, unite immediately before reaching the genital pore to form a very short vagina. At the point where

Translated from a notice, by Dr. J. von Kennel of Würzburg, in the Zoologisclier Anzeiger fur October 8, 1883 . the ovaries pass cver into the uterus is situated a small, nippleshaped gland and a spherical receptaculum seminis, the orifice of which every egg has to pass before it can enter the uterus. Now as a large number of embryos, from the "just furrowed" egg to the matured young, are always found in the uterus, it is very probable that each female Peripatus is only fertilised once.

The eggs of Peripatus contain no yolk, and seeing that in spite of this an animal of half the lenoth that it attains when adult develops itself in the uterus out of a small egg whose diameter is about $\mathrm{c}^{\circ} \mathrm{O} 4 \mathrm{~mm}$., there mu:t be some quite peculiar means for its nutrition, and this is the case to the most astonishing extent and in the most surprising manner.

As soon as the fertilised egg enters the thin portion of the uterus, a small enlargement takes place in its lumen, which is very narrow and is surrounded with very deep cylinder epithelia. Simultaneously with this the epithelium cells mass themselves a little together; the furrowed egg settles upon the epithelium, and immediately the lumen widens a good deal by the epithelial cells of the uterus becoming very depressed at that spot; so flattened do they become that they form a very thin pavementepithelium, whereas before and behind the "breeding-nidus" (Bruthöle) an embankment is formed by the thickening of the connective tissue of the uterine walls, so as nearly to fill up the uterine canal.

In this stage we find a hemispherical mass of homologous cells attached by a broad basis to the extraordinarily thin lining of the uterine cavity, a lining which has been formed out of the two cells that originally surrounded the egg. Presently a small depression develops in this hemispherical mass, and now the embryo forms something like the half of a hollow sphere, still consisting of but a few cells. Through the multiplication of these the hemisphere and the cavity in it become a little larger, and now a difference is perceptible between the cells of the embryo which are situated immediately upon the uterine epitnelium and the rest. The former, which I shall for brevity's sake here call basal cells, bave a long, narrow, and very compact nucleus, whereas the others have a large, circular, granular nucleus. The basal cells multiply, and in doing .so close the opening of the hemisphere, and form a layer which, lying between the embryo and the uterine epithelium, fastens the former to the latter. In the meantime the cells of the hemispherical mass have also multiplied to such a degree that the side looking towards the lumen of the uterus appears thickened by the cells mutually displacing each other.

In this stage the whole condition of the embryo resembles that of a flattened hollow sphere whose free wall bas been thickened; the longer diameter is $009 \mathrm{~mm}$., and the lesser $0^{\circ} 07 \mathrm{~mm}$. The basal cells of the embryo now spread themselves out a little, a few isolated ones come out from under the embryo, and thus enlarge the basis of attachment-they form an embryonic placenta. From them is also developed a very delicate membrane, which becomes closely applied to the uterine epithelium, and envelops the embryo-it may be shortly designated as amnion.

In the meanwhile changes are also going on in the uterus; the epithelium of the "breeding-nidus" has become a little thicker, the nuclei have increased in number, and a number of small dark brown pigment granules have developed and collected in the protoplasm of the flat cells, which for a long time mark off sharply the uterine epithelium from the embryonic portions.

The basal cells now multiply to a remarkable extent, partly so as to increase the size of the placenta, and partly in a direction perpendicular to it, forming a solid stalk upon which the embryo is pushed out free ints the lumen of the "breeding-nidus." The whole now forms a pyriform mass; the little head of the pear, the actual embryo, is, however, now no longer hollow; cells have been thrust in from the side furthest away from the stalk, which have filled up the whole "furrow cavity"; a sharp limit, however, is visible between them and the ectoderm at every point except the place where they have been invaginated; this point, which is comparable to the blastopore of other embryos, persists for a long time as the spot where material for the inner germinal layers is being continually provided by invagination, and is still demonstrable in embryos in which the form of Peripatus has long since been recognisable.

As soon as the "furrow cavity" has been filled up in the manner that has been described, a new cavity develops by fission in the central mass of cells. This is the definite visceral cavity. It develops by the embryo becoming composed of two layers (ectoderm and entoderm) in the half that is nearest to the 
stalk, whereas a thick prominence in which no differentiation can be made out, lies on the side furthest from the stalk. One must, however, regard its innermost cell layer as belonging to the entoderm, which also is continued into it.

While these changes have been taking place in the embryo, the "breeding-nidus" has increased considerably in size, the uterine epithelium has become thicker, and consists of a finely granular mass of protoplasm in which large round nuclei are found, and often lie in several layers one on top of another cell boundaries are no longer recognisable, and the pigment granules, which are disappearing, still form a narrow border towards the lumen of the uterus. Before and behind the breed. ing-nidus is almost altogether closed by great thickenings of the uterine walls. In the region of the breeding-nidus, however, there is a fissure in the connective tissue wall of the uterus which is probably a blood space.

The next stage in the development of the embryo may be shortly characterised as the mushroom form; the embryo becomes more clearly marked off from its stalk, and expands in all directions, but most of all in the direction of the longitudinal axis of the uterus, and now for the first time a bilateral symmetry can with certainty be made out ; the whole embryo resembles a mushroom with a thick stalk; the pileus is oval, as seen from above, and is a little broader at one end than at the other, and on the surface, towards the narrower end, is to be seen a shallow depression, which is limited towards the broader end by a slight prominence. This depression corresponds to the spot where the meso- and entoderms have been invaginated. There is as yet no opening to connect the visceral cavity with the outer world. The broader end of the embryo is the head end, the stalk side the back, the surface that projects into the lumen of the uterus the future ventral surface. In this stage a multiple layer of cells has already freed itself from the ectoderm, in front of the place where the invagination took place, and it lies, passing over behind into the undifferentiated cell-mas*, betw een the ecto- and entoderm, but is marked off from both of them by a distinct boundary.

Now while the embryo increases in length, more and more cells press in from the ectoderm at the spot that has been indicated, and specialise themselves towards the front into a real mesoderm, which, however, at first, and for a long time afterwards, occupies only the ventral aspect and also the lateral regions between ectoderm and entoderm, where it of cour:e multiplies independently.

In the meanwhile the thickening of the uterine epithelium has gone on; it now forms a ring, which surrounds three-quarters of the circumference of the breeding-nidus, and which as a broad zone divides the breeding-nidus into two halves, where, by the way, the epithelium bas been thickened to a considerable though a less degree; the pigment granules have now disappeared, the placenta has become very large, and the amnion, which has attained a high degree of development, and which consists of numerous large cells with large nuclei, lies closely applied to the uterine epithelium.

It is only when the embryo has still further increased in length, the part posterior to the stalk increasing very quickly in size, that the anus and mouth are formed, but not from a common opening, the blastopore of Balfour. The anus develops as a small fissure in the median line upon the prominence in front of the spot where the invagination has taken place; but the mouth develops far further forwards as an invagination of the ectoderm, consisting of only very few cells. This invagination has an inclination obliquely from behind forwards as it proceeds, and reaches the intestine, dividing its epithelium at the point of junction. This mouth invagination has as yet no lumen; this makes its appearance later, when the embryo already shows its segmentation plainly.

The first trace of this segmentation is the appearance of a cavity on each side in the oldest portions of the mesoderm, i.e. in the anterior extremity of the embryo, which splits the mesoderm plates into an inner membrane adjoining the intestine, and an outer one adjoining the ectoderm. These, however, are still connected to each other dorsally and ventrally. Soon afterwards a second pair of similar cavities develops behind, and so on from before backwards. These cavities that appear in segments, and which in their appearance closely resemble the original segmental formati on of a vertebrate animal, are the first rudiments of the body cavity. The different structures that develop out of its walls cannot be made out till later. With the exception of the further growth of the posterior end of the embryo, which soon curves itself, rolls itself up spirally, and finally forms manifold loops, and of the progress of the segmentation, and of the corresponding formation of cavities in the mesoderm, no changes take place in the interior of the emabryo. Embryos of $P$. Edwardsii of $\mathrm{I}-\mathrm{I} \cdot 5 \mathrm{~mm}$. length always present the same appearance on cross-section: an ectoderm slightly thickened on the ventral aspect, an extraordinarily thin entoderm, and between them on each side a pocket of mesoderm, whose walls touch each other in the ventral median line, and which in well-preserved embryos always are closely applied to the ectoderm, as well as to the entoderm, but which always present a sharplydefined boundary line. The anus is still nothing more than a narrow longitudinal fissure; the mouth has at last opened. Behind the anus is situated the depression, with the place where invagination has taken place.

Externally, on the other hand, a distinct segmentation of the body has taken place corresponding to the cavities in the mesoderm; the anterior segment (head segment) exceeds all the others in size; it consists of two symmetrical, spherical halves, to which the other segments are connected posteriorly; the ventral aspect of the head segment contains the mouth opening. I remark here that the mouth and anal opening that have been mentioned must be regarded as primary in Peripatus; the latter closes at a later stage to make room for a later-developing structure, and the former is thrust in further by a new invagination of the ectoderm, and becomes converted into the osophageal opening of the intestine. (These two observations require to be checked, and I shall have to do so by examining other embryos.) Each segment carries on each side a prominence which is the rudiment of the limbs that are developed later. The first pair of limbs is surrounded by a number of secondary papillæe, and is drawn into a wide mouth cavity to be utilised as a jaw; the second pair gives the papillæ on whose apices the large slime glands afterwards have their orifices. The tentacles are simply dorsal comtinuations or prolongations of both head cavities. Now at last, after the embryo has attained its full complement of segments, the first appearance of the nervous system can be made out as a paired ventral thickening of the ectoderm, which, soon separating itself from the ectoderm, extends in two separate threads from one end of the body to the other, only united by the brain, which has been developed in a similar manner in the head. The embryo itself, until it develops a definite gullet, is intimately connected by it; ectoderm, by means of the placenta with the maternal organism, and receives its nutriment through its dorsal stalk, which can be quite properly characterised as a navel-string, and which belongs to the first body segment. As soon, however, as it can swallow by help of its gullet, this connection is loosened, and the embryo now eats the food that is provided by the extraordinarily thickened uterine epithelium, which is rich in protoplasmic materials. At any rate, from that time forward coagulated protoplasm is always to be found in the intestine of the embryo, which was previously always empty.

This is, in a few words, an abstract of the most important results of my investigations up to date, which have been made upon something like a hundred young embryos. I here abstain for the sake of brevity from all discussion, but must, however, call attention to the fact how little Balfour's illustrations and the descriptions of the editors agree with the facts as they are here given. I hope it will not be long before I shall be able to lay before my fellow-workers my inve tigations, which I hope soon to complete, of these interesting and exceedingly anomalous phenomera of embryonic development, accompanied by numerous illustrations.

\section{UNIVERSITY AND EDUCATIONAI INTELLIGENCE}

OXFord.-By a mistake last week the stipend of the Professorship of Botany was given as 500l. instead of $700 l$. with a residence rent free. An election will take place in the course of Hilary term. The duty of the professor is to lecture and give instruction in botany. $\mathrm{He}$ will also have charge and supervision of the Botanical Garden and of the botanical collections belonging to the University; and it will be part of his duty to make such gardens and collections accessible to and available for the instraction of students attending his lectures. Candidates are requested to send to the 